\title{
The evolution of tracheobronchoplasty
}

Surgical support for patients with pulmonary emphysema and excessive airway collapse was first developed in the 1950s by Herzog and Nissen $(1,2)$. At the time, the terms tracheal dyskinesia, dystonia, hypotonia and prolapse were used in French and German scientific literature to describe what was thought to be the cause of obstruction to expiratory airflow in this patient population, and is more currently known as excessive central airway collapse (ECAC) (1-4). Naturally, the surgical technique of tracheobronchoplasty (TBP) evolved since, but the goal has remained the same: to restore a normal configuration of the airway by stabilizing the cartilaginous rings and/or the redundant posterior membranous wall.

The early experience of TBP was instrumental in laying the foundation for the current surgical practice, which most commonly consists of reinforcing the posterior membranous wall of the trachea and main stem bronchi with one or more pieces of appropriately sized prostheses. Initial variations in surgical technique did encompass the degree of airway dissection, the suturing technique and the type of splinting material. Rainer and colleagues in the US reported theirs using a running posterior transverse suture as originally described by Nissen, but with a reefing technique at the cartilaginous membranous junction (Figure 1). They also reported placement of the prosthesis on the antero-lateral surface of the trachea in a 270 degrees fashion, in cases of cartilaginous malacia (Figure 2). The authors used different types of prostheses including polyethylene, perforated heavy Marlex, and Dacron reinforced Silastic, among others $(5,6)$. They reported acceptable longterm results with an improvement in the maximum breathing capacity in 7 out of 19 pts. However, they experienced erosions into the esophagus and the aorta, prompting them to highlight the importance of a flexible pre-perforated splint that "allows early revascularization and tissue ingrowth from the surrounding mediastinal stroma" (7). The fear of such a disastrous complication is still valid today, and most authors currently advocate using a soft porous flexible mesh such as polypropylene, to avoid friction with the esophagus or development of seroma between the mesh and the tracheal wall $(8,9)$. Despite this, the threat of mesh infection and/or erosion into the trachea is still real, as placement of intraluminal sutures to anchor the prosthesis carries the risk of bacterial contamination. This prompted some to use absorbable sutures and/or biological meshes such as acellular dermis, but either has the potential to affect the durability of the repair and the long-term outcomes $(9,10)$. Tracheopexy of the membranous wall to the posterior longitudinal ligament does not involve prosthesis placement and practically eliminates the risk of erosion, but the experience is mostly limited to the pediatric population and the technique
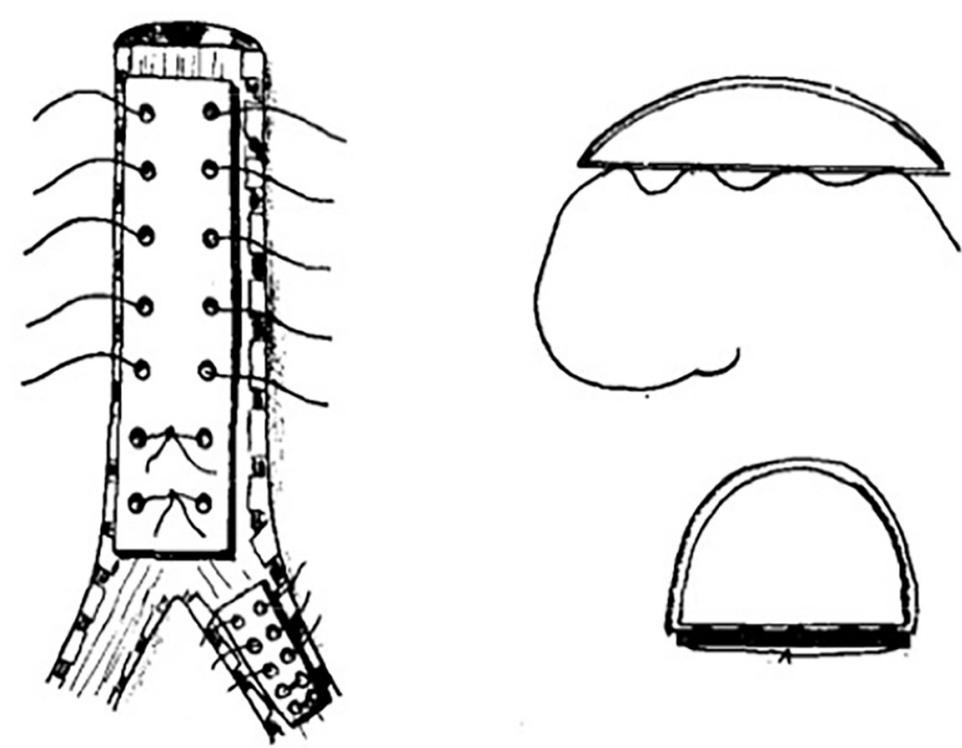

Figure 1 Configuration of the sutures and prosthesis placement on the posterior wall of the trachea and main stem bronchi. From Rainer et al. (5), with permission. 


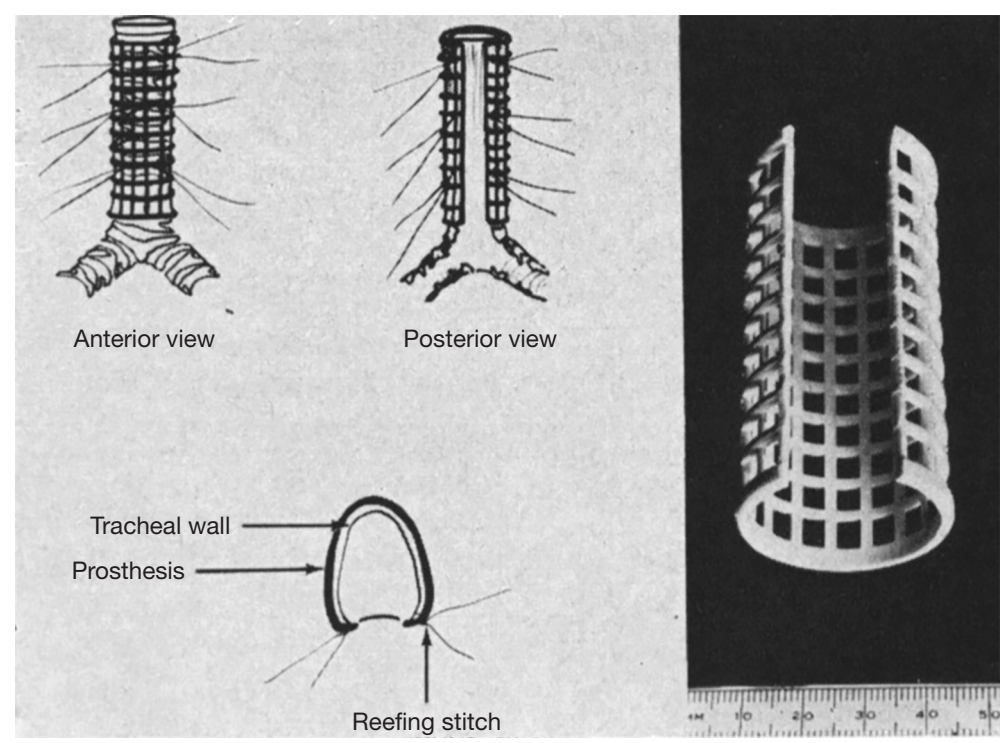

Figure 2 Antero-lateral placement of the tracheal prosthesis in cases of cartilaginous malacia. From Rainer et al. (6), with permission.

mainly addresses malacia of the trachea itself $(11,12)$.

Traditionally performed via a generous right thoracotomy through the fourth intercostal space, the recent adoption of the robotic platform in TBP has the potential to transform the surgical care of ECAC (10). The main advantages of the robotic approach include excellent visualization and filtered wristed motion that allows precise and accurate dissection and suturing even in challenging angles. Additional significant benefits include better exposure of the airway, especially the left main stem bronchus, and much improved ergonomics for the operating surgeon. Regardless of the technique or the approach, adjustment in the suture placement can be made depending on the underlying pathophysiology of ECAC, allowing more lateral downsizing in cases of pronounced cartilaginous tracheobronchomalacia (TBM) mainly affecting the rings, compared to cases of excessive dynamic airway collapse (EDAC) where the transverse diameter of the airway is not particularly enlarged.

In our practice, we currently favor the robotic approach and we use interrupted absorbable sutures to anchor 3 pieces of soft porous polypropylene meshes to the posterior membranous wall of the trachea, right and left main stem bronchi. We have had no infections or erosion complications in 9 cases thus far, and we prospectively follow the patients with physiologic testing and respiratory questionnaires to ensure the durability of the surgical repair. We strongly believe patients with ECAC are best served in a multidisciplinary setting that ensures long-term follow-up of both subjective and objective treatment outcomes.

With improved public awareness and more widespread recognition of the disease in the medical community, TBP will likely be performed more frequently in the future. Patient selection will remain paramount to ensure good correlation between the clinical picture and radiographic or bronchoscopic evidence of airway collapse in a population with frequent confounders such as asthma, chronic obstructive pulmonary disease (COPD), sleep apnea and obesity.

Future advancements and innovations can help address some of the remaining diagnostic and therapeutic challenges of this under-recognized condition. Although pulmonary function tests are helpful and an integral part of the work-up, there are still no pathognomonic physiologic diagnostic testing for ECAC. Dynamic video chest computed tomography or even magnetic resonance imaging can help standardize the evaluation of airway collapsibility, and 3D printing of custom biological but durable prosthesis would practically eliminate the risk of infection or erosion. Less invasive approaches can even conceivably address tracheal cartilaginous malacia via an extended mediastinoscopy approach, and cases of isolated EDAC could eventually be treated through advanced endoscopic techniques. Gene therapy or other biological agents would hopefully be developed one day for ECAC patients with known genetic defects of the cartilaginous matrix.

In this series, we review the clinical management of ECAC and technical aspects of TBP and other treatment modalities. 
We emphasize the importance of a multidisciplinary and comprehensive evaluation of patients with ECAC, and the need to reserve surgery for those with significant symptoms who fail optimum medical treatment.

We would like to thank all the authors for their valuable contributions to this special series, as well as the editorial office of the Fournal of Visualized Surgery for their support. We truly believe this collection of articles, pictures and videos represent one of the most complete and comprehensive reviews of TBP for ECAC.

\section{Acknowledgments}

Funding: The article was supported by the Fox Chase Cancer Center Core Grant (NIH P30 CA006927).

\section{Footnote}

Provenance and Peer Review: This article was commissioned by the editorial office, fournal of Visualized Surgery for the series "Tracheobronchoplasty". The article did not undergo external peer review.

Conflicts of Interest: Both authors have completed the ICMJE uniform disclosure form (available at https://jovs.amegroups. com/article/view/10.21037/jovs-21-69/coif). The series "Tracheobronchoplasty" was commissioned by the editorial office without any funding or sponsorship. CTB served as the unpaid Guest Editor of the series. AA served as the unpaid Guest Editor of the series and serves as the unpaid editorial board member of Fournal of Visualized Surgery from July 2020 to June 2022. The authors have no other conflicts of interest to declare.

Ethical Statement: The authors are accountable for all aspects of the work in ensuring that questions related to the accuracy or integrity of any part of the work are appropriately investigated and resolved.

Open Access Statement: This is an Open Access article distributed in accordance with the Creative Commons AttributionNonCommercial-NoDerivs 4.0 International License (CC BY-NC-ND 4.0), which permits the non-commercial replication and distribution of the article with the strict proviso that no changes or edits are made and the original work is properly cited (including links to both the formal publication through the relevant DOI and the license). See: https://creativecommons.org/ licenses/by-nc-nd/4.0/.

\section{References}

1. Herzog H, Nissen R. Erschlaffung und exspiratorische invagination des membraneösen teils der intrathorakalen luftröhre und der hauptbronchien als ursache der asphyktischen anfälle beim asthma brornchiale und bei der chronischen asthmoiden bronchitis des lungenemphysems. Schweiz Med Wochenschr 1954;84:217.

2. Nissen R. Tracheoplastik zur beseitigung der erschlaffung des membranösen teils der intrathorakalen luftrühre. Schweiz Med Wochenschr 1954;84:219-21.

3. Herzog H. Expiratory stenosis of the trachea and large bronchi caused by hypotonia of the pars membranacea in obstructive emphysema. Differential diagnosis. Pressure/caliber diagrams. Therapy by plastic surgery. Rev Prat 1963;13:3875-85.

4. Huzly A. Tracheal graft using the Herzog-Nissen method as treatment for tracheo-bronchial dystonia. J Fr Med Chir Thorac 1966;20:665-71.

5. Rainer WG, Feiler EM, Kelble DL. Surgical technic of major airway support for pulmonary emphysema. Am J Surg 1965;110:786-9.

6. Rainer WG, Hutchinson D, Newby JP, et al. Major airway collapsibility in the pathogenesis of obstructive emphysema. J Thorac Cardiovasc Surg 1963;46:559-67.

7. Rainer WG, Newby JP, Kelble DL. Long term results of tracheal support surgery for emphysema. Dis Chest 1968;53:765-72.

8. Gangadharan SP, Bakhos CT, Majid A, et al. Technical aspects and outcomes of tracheobronchoplasty for severe tracheobronchomalacia. Ann Thorac Surg 2011;91:1574-80; discussion 1580-1. 
9. Wright CD, Mathisen DJ. Tracheobronchoplasty for tracheomalacia. Ann Cardiothorac Surg 2018;7:261-5.

10. Lazzaro R, Patton B, Lee P, et al. First series of minimally invasive, robot-assisted tracheobronchoplasty with mesh for severe tracheobronchomalacia. J Thorac Cardiovasc Surg 2019;157:791-800.

11. Shieh HF, Smithers CJ, Hamilton TE, et al. Posterior tracheopexy for severe tracheomalacia. J Pediatr Surg 2017;52:951-5.

12. Kamran A, Hamilton TE, Zendejas B, et al. Minimally invasive surgical approach for posterior tracheopexy to treat tevere tracheomalacia: lessons learned from initial case series. J Laparoendosc Adv Surg Tech A 2018;28:1525-30.

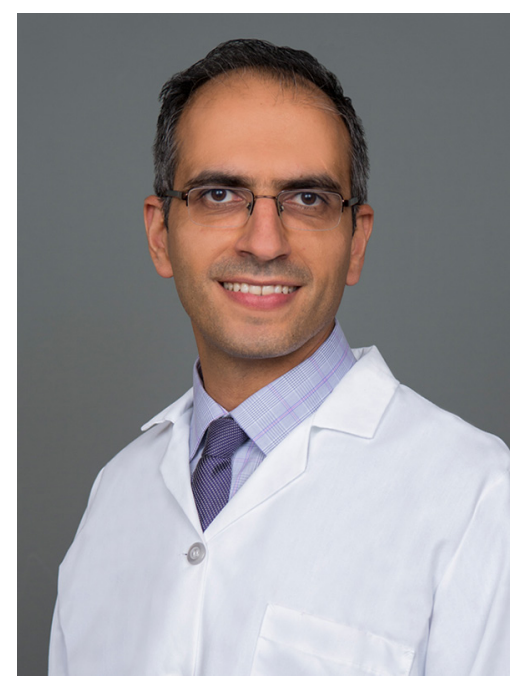

Charles T. Bakhos

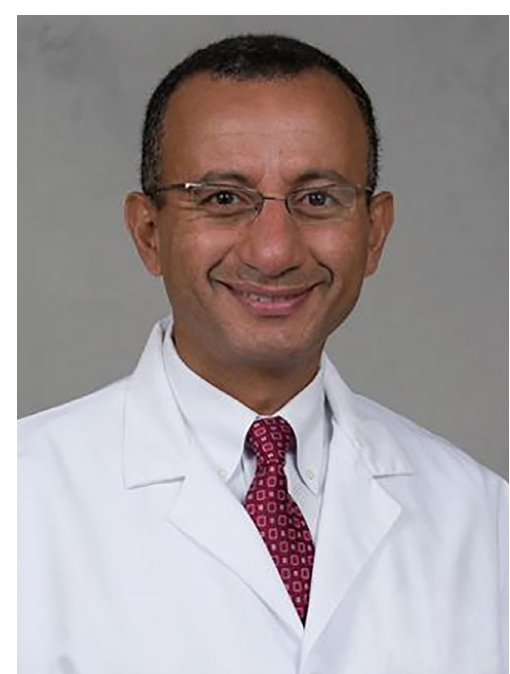

Abbas E. Abbas

Charles T. Bakhos ${ }^{1,2}$, MD, MBA, MS, FACS

${ }^{1}$ Department of Thoracic Medicine and Surgery, Temple University Hospital, Lewis Katz School of Medicine, Philadelphia, PA, USA;

${ }^{2}$ Fox Chase Cancer Center, Department of Surgical Oncology, Philadelphia, PA, USA.

(Email: Charles.bakbos@tubs.temple.edu)

Abbas E. Abbas ${ }^{3}$, MD, MS, FACS

${ }^{3}$ Department of Surgery, Lifespan Health System Hospitals, Brown University, Warren Alpert Medical School,

Providence, RI, USA.

(Email: abbas_abbas@brown.edu)

Received: 30 December 2021; Accepted: 11 January 2022; Published: 20 April 2022.

doi: $10.21037 /$ jovs-21-69

View this article at: https://dx.doi.org/10.21037/jovs-21-69

doi: $10.21037 /$ jovs-21-69

Cite this article as: Bakhos CT, Abbas AE. The evolution of tracheobronchoplasty. J Vis Surg 2022;8:12. 